\title{
CORPOS GORDOS (IN)VISIBILIZADOS NA LINGUÍSTICA APLICADA
}

\author{
FAT BODIES (IN)VISIBILIZED IN APPLIED LINGUISTIC
}

\author{
Viviane Pires Viana Silvestre ${ }^{1}$ \\ [Orcid: https://orcid.org/0000-0003-2234-9046] \\ Wilker Ramos-Soares ${ }^{2}$ \\ [Orcid: https://orcid.org/0000-0002-7182-7991] \\ Barbra Sabota ${ }^{3}$ \\ [Orcid: https://orcid.org/0000-0002-3100-259X] \\ DOI: https://doi.org/10.30612/raido.v14i36.11715
}

RESUMO: Este trabalho se constitui como uma pesquisa bibliográfica qualitativointerpretativista realizada a partir do levantamento de estudos no Catálogo de Teses e Dissertaçôes da CAPES, na Coleçăo de Periódicos da biblioteca eletrônica SciELO e na Biblioteca Digital de Teses e Dissertaçóes, a fim de entender se e como pesquisas relacionadas ao corpo gordo como uma questâo social compóem os trabalhos da Linguística Aplicada no Brasil. Para tanto, discutimos alguns fenômenos históricos e sociais na construçăo da imagem estigmatizada do corpo gordo, por meio de um breve apanhado de conceitos ligados à gordofobia, e traçamos como percurso metodológico a busca nas plataformas selecionadas por 10 palavras-tema que abrangem o ativismo gordo. Após o refinamento do levantamento feito nas três bases bibliográficas, considerando a grande área "Linguística, Letras e Artes", as 10 palavras-tema escolhidas e sua relaçăo com a Linguística Aplicada, foram encontrados quatro trabalhos. A análise desses trabalhos aponta para uma lacuna de estudos sobre corpos gordos no escopo da Linguística Aplicada brasileira que tenha um olhar mais plural para as dimensôes de nosso país, o que indica a necessidade de que a temática gordoativista seja incorporada aos estudos da Linguística Aplicada, especialmente ao repertório d@s que estâo engajad@s no contexto de educaçăo linguística, contribuindo, assim, para a construçăo de uma sociedade menos gordofóbica.

Palavras-Chave: Linguística Aplicada; Corpo Gordo; Gordofobia; Gordativismo.

ABSTRACT: This work is designed and developed as a qualitative-interpretative

1 Doutora em Letras e Linguística pela Universidade Federal de Goiás, com estágio de pós-doutoramento no mesmo Programa. Docente do curso de Letras: Português e Inglês e do Programa de Pós-Graduaçăo Interdisciplinar em Educaçấo, Linguagem e Tecnologias da Universidade Estadual de Goiás, AnápolisGO, Brasil.E-Mail: viviane.silvestre@ueg.br.

2 Graduando do curso de Letras: Português e Inglês da Universidade Estadual de Goiás, Anápolis-GO, Brasil.E-Mail:w.rsp@outlook.com.

3 Doutora em Letras e Linguística pela Universidade Federal de Goiás, com estágio de pós-doutoramento no Programa de Pós-Graduaçăo em Linguística Aplicada da Universidade de Brasília. Docente do curso de Letras: Português e Inglês e do Programa de Pós-Graduaçăo Interdisciplinar em Educaçăo, Linguagem e Tecnologias da Universidade Estadual de Goiás, Anápolis-GO, Brasil.E-mail: barbra.sabota@ueg.br. . 
bibliographic research carried out from the search for studies in the three main scientific database in our country: CAPES Theses and Dissertations Catalog, SciELO electronic journals library and the Digital Theses and Dissertations Library, in order to understand if and how research related to the fat body as a social issue is part of the work of Applied Linguistics in Brazil. To this end, we discuss some historical and social phenomena in the construction of the stigmatized image of the fat body, through a brief overview of concepts related to fatphobia, and we trace as a methodological path the search on the selected platforms for ten theme words that cover fat activism matters. After refining the survey carried out in the three bibliographic bases, considering the large area "Linguistics, Language and Arts", the ten chosen theme words and their relationship with Applied Linguistics, four works were found. The analysis of these works points to a gap in studies on fat bodies in the scope of Brazilian Applied Linguistics which have a more plural look at the dimensions of our country. To this extent, that indicates the need for the fat-activist theme to be incorporated into the studies of Applied Linguistics, mainly to the repertoire of those who are engaged in the context of language education, thus contributing to the construction of a less fatphobic society.

Keywords: Applied Linguistics; Fat Body; Fatphobia; Fat Actvism

\section{REFLEXÕES INICIAIS}

Como ponto de partida das discussóes que trazemos neste texto, propomos a você leit@r ${ }^{4}$ pensar nas seguintes questōes: Os direitos ditos “humanos" se restringem a algumas pessoas ou se estendem a todas? Quando se depara com pessoas privadas desses direitos, como costuma agir? Ao pensar nessas pessoas, os sujeitos gordos estăo incluídos? Na sequência, pedimos que leia atentamente a colagem digital que propomos na Figura 1 e reflita sobre mais alguns questionamentos: Com que frequência essas problemáticas săo levadas em consideraçăo em suas vivências cotidianas, profissionais e de pesquisa? Que recorte da colagem mais lhe incomoda? Que reflexôes ela suscita? Que reverberaçôes podem ter em suas vivências socioculturais, profissionais e acadêmicas? Por quê? Com as possíveis inquietaçôes que surgiram a partir do exercício que propomos é que gostaríamos que seguisse a leitura deste texto.

4 Optamos pelouso de “@” para marcaçăo inclusiva de gênero porque, em consonância com Marra e Rezende (2018), acreditamos que esse símbolo desnaturaliza as construçóes dicotômicas que circunscrevem a compreensâo do gênero social refletido na escrita. 
Figura 1: Colagem digital Corpos gordos na vida social

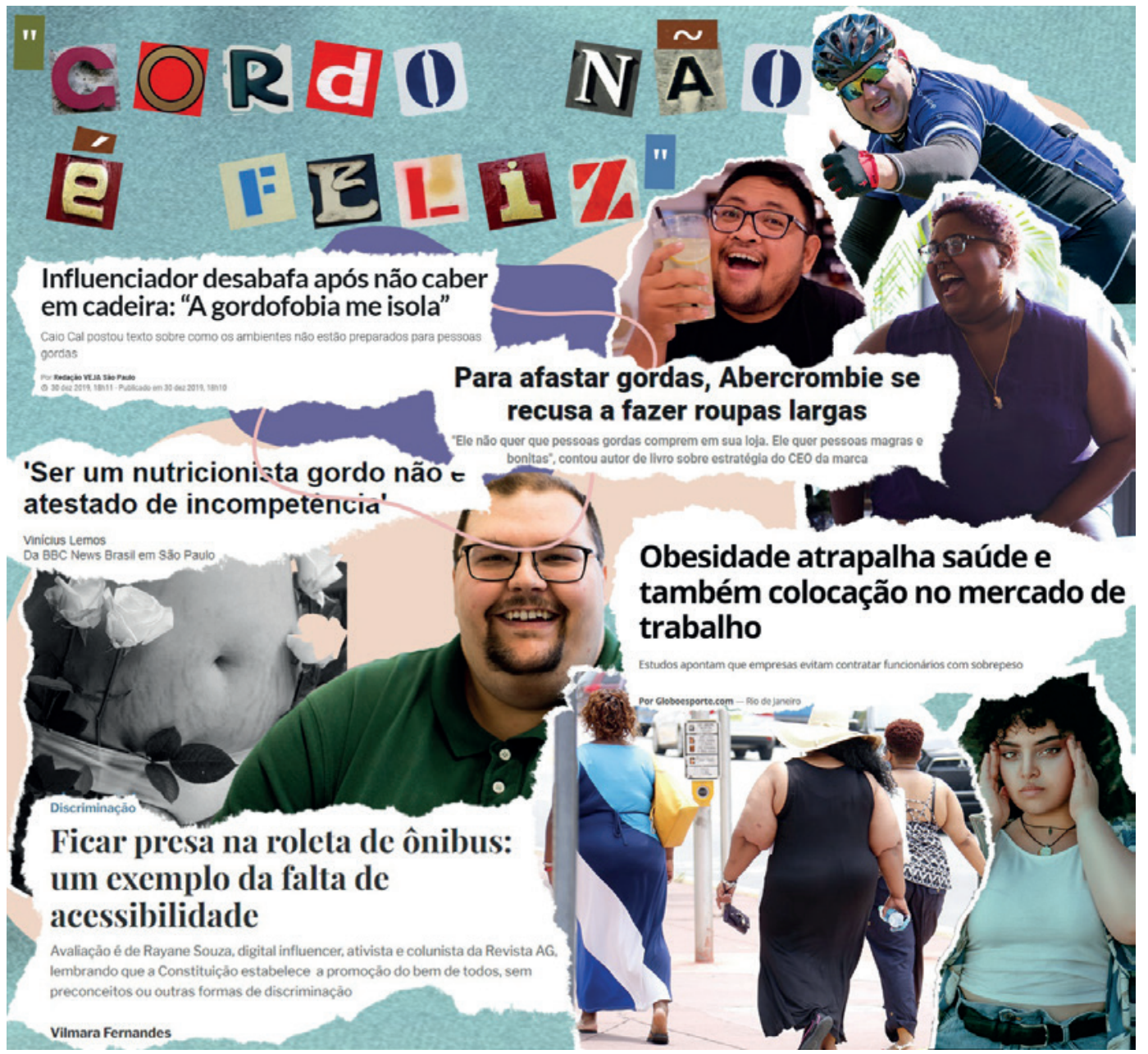

Fonte: Elaborado pelo designer João Peixoto, a pedido d@s autor@s, com arquivos do banco de imagens gratuitas Unplash.

A colagem digital que inaugura este texto revela apenas alguns fragmentos das vivências a que estăo submetidos sujeitos gordos em nossa sociedade. Direitos básicos como locomoçấo, acessibilidade e até mesmo a escolha de uma profissâo săo dificultados para pessoas cujo contorno corporal excede o padrăo esperado socialmente. Essa é uma indicaçăo evidente de que, de fato, os diretos humanos năo atendem a tod@s de modo igualitário. Estamos convencid@s de4 que os sofrimentos, privaçôes e opressôes estruturais vividas por pessoas gordas - nomeadamente gordofobia - se constituem e săo cotidianamente nutridas na e pela linguagem. Corpos gordos estăo nos mais diversos espaços da vida social e sua estigmatização e hostilizaçấo săo desafios atuais e prementes que têm inquietado tanto ativistas sociais engajad@s na luta contra a gordofobia - aqui denominada gordoativismo - como pesquisador@s da área de Ciências Sociais e Humanas.

Por outro lado, Bastos e Pessoa (2019) nos alertam que temas como padróes de beleza e gordura corporal - que estăo imbricados no amplo escopo da temática gordoativista - náo sâo mencionados nos domínios da Linguística Aplicada (doravante LA) em sua vertente crítica (PENNYCOOK, 2001). Guiad@s por nossa filiaçăo à educaçăo 
linguística crítica5 ${ }^{5}$ pelas experiências de vida do segundo autor como uma pessoa

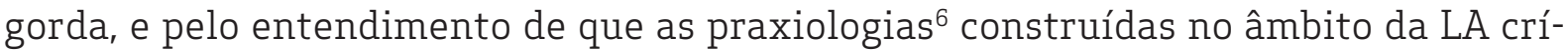
tica săo localizadas, ou seja, pesquisador@s e suas subjetividades săo fundamentais (MOITA LOPES; FABRÍCIO, 2019), trazemos à tona a pauta social de opressāo ao corpo gordo como um desafio do mundo atual que pode interessar à LA, na intençăo de contribuir para que essa pauta seja integrada ao repertório d@s que estâo engajad@s no contexto de educaçáo linguística.

Assim, neste estudo, nos dedicamos a realizar um levantamento bibliográfico que se constituiu em um mapeamento de trabalhos brasileiros que discutem o corpo gordo no âmbito da Linguística Aplicada disponíveis no Catálogo de Dissertaçôes e Teses da CAPES, na Coleçâo de Periódicos da biblioteca eletrônica SciELO e na Biblioteca Digital Brasileira de Teses e Dissertaçôes (BDTD). O principal intuito deste estudo é entender se e como pesquisas relacionadas ao corpo gordo como uma questăo social compóem os trabalhos da LA no Brasil. Isso feito, podemos analisar a pertinência ou náo dessa agenda de pesquisa para a área, em especial para as praxiologias no tocante à educaçăo linguística.

Cabe registrar que as problematizaçôes que trazemos neste texto nâo negam a importância de hábitos de vida e alimentaçấo saudáveis. Uma das pautas mais importantes do gordoativismo é justamente desassociar o corpo gordo do estigma de um corpo doente. A ressalva que fazemos busca dissipar o preconceito que recai sobre o corpo gordo, via de regra tomado como desviante e apto a sofrer comentários de demérito a partir da aparência "fora da norma" ou do padrâo estético vigente. A gordura corporal é lida a partir da lente político-econômica construída socialmente, ou seja, ela năo tem um valor absoluto, mas sim recebe atributos diversos em razâo do contexto histórico e/ ou cultural em que é vista, o que implica dizer que a gordura é uma construçâo cultural. Nesse sentido, a relaçâo dos indivíduos com a aparência física opulenta muda de acordo com os valores construídos e praticados a seu tempo. Historicamente, esse significado tem se mostrado fluido e alterado a partir de relaçóes de poder (WANN, 2009), o que nos leva a perceber que estudos sobre o corpo gordo precisam ser entendidos de modo interseccionado (WANN, 2009), semelhantemente aos estudos sobre raça, gênero, sexualidade, entre outros.

Este texto está organizado em outras quatro seçōes além desta introdutória. No tópico seguinte, discutimos alguns termos ligados à temática gordoativista, relacionando-os a algumas discussôes caras à LA crítica. Na sequência, descrevemos como se deu o percurso metodológico do estudo. A seguir, analisamos se e como o corpo gordo tem sido problematizado no âmbito da LA no Brasil, com base nos resultados do levantamento bibliográfico realizado. Finalizamos com algumas consideraçôes a respeito dos resultados encontrados e argumentamos em favor da causa gordoativista em praxiologias no escopo da LA brasileira.

\footnotetext{
$5 \quad$ Este trabalho se vincula às açōes do grupo de estudos INTEGRA - Perspectivas Críticas em Educaçăo Linguística e Letramentos (UEG - UnU-Ânápolis CSEH), parte integrante do grupo de pesquisa "Rede Cerrado de formaçăo crítica de professoras/es de línguas" (UFG, UEG, UnB, UFMT), cadastrado no CNPQ (http://dgp.cnpq.br/dgp/espelhogrupo/8249339597981939), vinculado à Rede de Pesquisa do "Projeto Nacional de Letramentos: Linguagem, Cultura, Educaçăo e Tecnologia", com sede na Universidade de Sáo Paulo e coordenado por Walkyria Monte Mór e Lynn Mário T. Menezes de Souza. Este artigo é uma versâo ampliada do Trabalho de Conclusăo de Curso do segundo autor (RAMOS-SOARES, 2019).

6 Entendemos o termo "praxiologias" a partir da noçâo freiriana de práxis educativa.
} 


\section{GORDOATIVISMO E LINGUÍSTICA APLICADA: AMPLIANDO RELAÇÕES7}

Bauman (2010, p. 33, ênfase no original) afirma que "em sua fase líquido-moderna, a cultura é feita na medida da liberdade de escolha individual (voluntária ou imposta como obrigaçâo). É destinada a servir às exigências desta liberdade. A garantir que a escolha continue a ser inevitável: uma necessidade de vida e um dever". Observando as palavras que o autor optou por destacar, percebemos que a cultura atual năo favorece o coletivo e busca impor sutilmente padróes que se assemelhem a escolhas, haja vista que esta cultura está inserida em um contexto de capitalismo parasitário (que se hospeda entre nós e nos destrói), caracterizada por uma "sociedade de consumidores" (BAUMAN, 2010, p. 33). O consumo aqui se refere tanto a bens materiais quanto imateriais; é importante desejar para consumir, portanto sempre haverá modelos inatingíveis a serem alcançados e modos vendáveis de se chegar até eles. A escolha inevitável do primeiro trecho se refere a esta forma de estar pres@ nas garras de um sistema que nos corrói e nos enreda de modo a ser impossível escapar. Os "cuidados" com o corpo há tempos refletem esta posiçâo. Independentemente da posiçâo ideológica que um indivíduo se encontre, sempre haverá um produto e/ou um ideal para ser consumido e postulando uma "contradiçấo entre a máxima busca de prazer e a máxima aptidâo física" (BAUMAN, 2010, p. 85). Cabe lembrar que esta ideia é amplamente difundida pela mídia (convencional e digital), alimentando esse capitalismo ainda mais fortemente. Isso considerado, ao nos referirmos ao corpo hegemonicamente aceito e almejado, temos o corpo magro, alto, malhado; à margem, é posto o corpo gordo, como sinônimo de "descuido", "doença", "feiúra".

O processo de marginalizaçăo, e consequente estigmatizaçăo e discriminaçăo, do corpo gordo em diferentes esferas socioculturais tem sido conceituado como gordofobia. ${ }^{8}$ Nesse sentido, a gordofobia se materializa por meio de uma opressâo estrutural, que envolve diferentes facetas, como acessibilidade, mobilidade, patologizaçăo, vestuário, mercado de trabalho, preterimento afetivo, representatividade, com consequências diretas na qualidade de vida de pessoas gordas. Diz respeito, por exemplo, ao fato de uma pessoa gorda: a) ser privada de espaços sociais por năo ter acessibilidade para a transiçăo de seu corpo (tais como assentos de aviăo, cintos de segurança, catracas de ônibus); b) năo encontrar roupas, sapatos e afins disponíveis, e paralelamente ser julgada, menosprezada, estigmatizada pelo tamanho do seu corpo; c) na infância, passar por repressâo e privaçâo de determinados alimentos com o intuito de manter a "saúde" (PETROSKI; PELEGRINI; GLANER, 2012); d) na fase da adolescência, ser vítima de chacotas e bullying dentro das escolas (BASTOS; PESSOA, 2019); e) na maturidade, ser julgada como menos produtiva e com imagem negativa no mercado de trabalho; entre muitos outros exemplos que poderíamos listar. Como posto por Caetano (2019, p. 15, ênfase no original), a percepçăo que fica é que “o corpo gordo năo 'cabe' nos moldes da formaçấo social em que vivemos".

Parte das discussōes realizadas nesse tópico foram apresentadas na II Jornada Internacional de Linguística Aplicada Crítica (JILAC/UnB 2019) e no Seminário de Pesquisa, Pós-Graduaçáo, Ensino e Extensăo da UnU-Anápolis CSEH (SEPE/UEG 2019).

8 Esse é um conceito complexo, transdisciplinar e ainda embrionário na academia (RANGEL, 2018). 
Em contrapartida, têm sido crescentes as açóes de militância voltadas contra a gordofobia no Brasil, especialmente em meios virtuais, como blogs e outras redes sociais (RANGEL, 2017). O gordoativismo - ou ativismo gordo (RANGEL, 2017, 2018) - (in) surge para "questionar a crescente estigmatizaçăo (estando o processo de estigmatizaçâo intimamente ligado ao processo de patologizaçăo [...]) que os corpos gordos passam a sofrer no ocidente desde o fim do século XIX até os dias de hoje" (RANGEL, 2018, p. 140). Trata-se de um movimento que visa a inclusăo e tem como pauta principal o corpo gordo, com forte influência dos estudos feministas e pós-modernos, que reivindicam pautas sociais de grupos identitários marginalizados socialmente. Tais militâncias ativistas configuram-se como um espaço de acolhimento e escuta sensível a partir da partilha de vivências, mostrando-se como um exercício revolucionário e emancipatório para pessoas gordas pararem de se odiar (GURGEL, 2018), contribuindo, assim, para movimentos de mudança social de percepçăo do corpo gordo. Vale ressaltar, no entanto, que se trata de um movimento multifacetado, plural e divergente.

O estudo específico sobre corpos gordos que levam em consideraçâo nâo apenas questōes biomédicas e patológicas, mas, sim, fatores sociais, culturais e políticos tem sido caracterizado como "fat studies" - "estudos gordos", em uma traduçấo livre - (COOPER, 2010). Insere-se em um campo interdisciplinar, que busca compreender o corpo gordo a partir de uma perspectiva social. Nesse sentido, um dos grandes desafios é desconstruir a relaçăo imediata entre corpo gordo e corpo doente, imagem essa construída sócio-historicamente e que se preza a estigmatizar e patologizar esse corpo. Desde que uma possível "epidemia de obesidade" foi alarmada por médic@s e promotor@s de saúde nos Estados Unidos no final do século XX, essa imagem tem sido construída e reforçada. Na ocasiăo, os parâmetros usados para categorizar "sobrepeso" ou "obesidade" era a medida de índice de massa corporal (IMC) - ainda muito presentes atualmente - e o fenômeno foi visto como uma crise de saúde pública, afirmando que pessoas fora dessa "medida ideal" sofreriam de taxas mais altas de doenças e, com isso, morreriam prematuramente. Por essa razăo, "o ativismo gordo nega as definiçóes de 'acima do peso' e de 'obesidade'" (RANGEL, 2018, p. 70, ênfase no original).

Antes de prosseguir nossa discussăo, sintetizamos no Quadro 1, a seguir, cinco termos - três deles usados frequentemente em inglês - que se conectam direta ou indiretamente ao processo de constituiçăo do gordoativismo.

\section{Quadro 1: Termos ligados direta ou indiretamente ao gordoativismo}

\begin{tabular}{|l|l|}
\hline Pressão estética & $\begin{array}{l}\text { Refere-se a um padrão de beleza estética imposto socialmente, padrão esse que é } \\
\text { inalcançável, inatingível. Mesmo as pessoas que estão bem próximas a esse padrão - } \\
\text { caso de modelos e artistas que exibem seus corpos magros e malhados em capas de } \\
\text { revistas e afins - sofrem com essa pressão imposta a elas (VASCONCELOS; SUDO; } \\
\text { SUDO, 2004). Vale ressaltar que o padrão de beleza é imposto aos variados gêneros, } \\
\text { porém as mulheres sofrem muito mais pressão pelo "corpo perfeito" se comparadas } \\
\text { aos homens, por exemplo. }\end{array}$ \\
\hline Headless fatty & $\begin{array}{l}\text { Diz respeito a imagens, criadas especialmente pelas mídias estadunidenses, que } \\
\text { mostram corpos de pessoas gordas sem que apareçam seus rostos, um processo que } \\
\text { tinha como intuito "desumanizar" aquele corpo e distorcer a imagem com estigmas } \\
\text { sociais de pessoas gordas como ignorantes, preguiçosas, gulosas e feias (TARDIF, } \\
\text { 2019). Essas imagens foram - e ainda são - usadas com a finalidade de vendas de } \\
\text { produtos para "resolver" o problema da gordura. }\end{array}$ \\
\hline
\end{tabular}




\begin{tabular}{|l|l|}
\hline Fat acceptance & $\begin{array}{l}\text { Movimento social que promove campanhas que defendem iniciativas de aceitação do } \\
\text { corpo gordo, tendo forte influência do feminismo. }\end{array}$ \\
\hline Body positive & $\begin{array}{l}\text { Em uma tradução livre, quer dizer "corpo positivo", surge como uma resposta a } \\
\text { campanhas que pregavam a "barriga negativa", em aversão ao corpo gordo, com o } \\
\text { objetivo de conscientizar as pessoas sobre padrões de beleza agressivos. Seu maior } \\
\text { lema é: "Meu corpo, minhas regras". }\end{array}$ \\
\hline Corpo livre & $\begin{array}{l}\text { Versão brasileira do Body Positive, militantes gordoativistas brasileir@s criam } \\
\text { campanhas, principalmente no verão, com o intuito de livrar seus corpos de amarras } \\
\text { sociais, pregando um "corpo livre". O movimento tem como madrinha um dos } \\
\text { principais e mais importantes nomes do ativismo gordo no Brasil: a digital influencer, } \\
\text { escritora e youtuber Alexandra Gurgel. }\end{array}$ \\
\hline
\end{tabular}

Fonte: Elaborado pel@s autor@s.

Notamos, entăo, que "entender o corpo gordo é primeiramente entender a sua construçâo social, construçâo esta que, muitas vezes, nos escapa, surgindo entâo como algo naturalmente dado" (VASCONCELOS; SUDO; SUDO, 2004, p. 9). Nesse sentido, o surgimento desses movimentos abre espaços para discussăo de uma série de outras problemáticas, tais como anorexia (distúrbio alimentar motivado por um desejo patológico de emagrecer e um forte medo de engordar), bulimia (transtorno alimentar motivado pela compulsáo por comida e tomada de medidas radicais para evitar o ganho de peso - normalmente, isso significa expurgo), transtorno do comer compulsivo (síndrome em que a comida é usada para lidar com problemas psicológicos e emocionais), vigorexia (síndrome que causa uma insatisfaçâo constante com o corpo, levando à prática exaustiva de exercícios físicos), alotriofagia (síndrome que faz com que a pessoa mastigue substâncias que náo têm valor calórico, como gelo, argila, terra ou papel), entre outros. Em consonância com o exposto, vivemos em uma sociedade que:

[...] ao valorizar a magreza, transforma a gordura em um símbolo de falência moral, e o gordo, mais do que apresentar um peso socialmente inadequado, passa a carregar um caráter pejorativo [...]. [Essa imagem no corpo gordo] tornou-se, deste modo, na sociedade contemporânea, individualizada com o predomínio de uma ideologia individualista, fundamentada pela cultura do narcisismo, onde o indivíduo passa a ser o seu valor supremo, com um projeto do 'eu' moderno voltado, cada vez mais, para dentro e para cuidar de si, passando a ser um indivíduo avesso a diferenças (VASCONCELOS; SUDO; SUDO, 2004, p. 4, ênfase no original).

Ao trazermos à baila a intrínseca relaçăo entre linguagem, subjetividade e sociedade, entendemos que essa percepçâo social do corpo gordo é discursivamente construída e reiterada. Como nos alerta Morgan (2007), na visăo pós-estruturalista de linguagem, os significados (que săo instáveis) que temos de nós mesm@s e d@s outr@s săo produzidos dentro de discursos. Nesse sentido, "o indivíduo se torna 'descentralizado'" (MORGAN, 2007, p. 952, ênfase no original) e as identidades (ou subjetividades) sâo tidas como práticas sociais. Defendemos, assim, a linguagem como produtora de identidades ao invés da ideia de identidade como construto pré-existente que se reflete no uso da linguagem - o que nos leva a refutar visóes fundamentalistas e essencialistas no entendimento da relaçâo entre linguagem, subjetividade e sociedade. Isso posto, compreender a funçăo da linguagem na vida social e, consequentemente, na construçăo e circulaçăo de discursos sobre corpos gordos nos permite questionar e fomentar movimentos de mudança em torno desses construtos. Nesse sentido, um desafio que se 
coloca (dentre outros tantos) é fazer com que essas problematizaçōes cheguem àquel@s a quem nosso trabalho se presta: alun@s e/ou professor@s de línguas. Chegamos, assim, a um elo central de ligaçáo das discussôes em torno do corpo gordo - entendido como diferente e marginalizado estrutural e também discursivamente - e a LA.

Há pelo menos duas décadas, Pennycook (2001) já apontava para três possíveis respostas em termos pedagógicos e de pesquisas às diversas formas de diferença no escopo da LA crítica. A primeira delas, inclusivity, diz respeito à inclusâo (representatividade) da diversidade/diferença em textos, nas atividades de sala de aula de línguas e nas pesquisas da área. No entanto, o autor acredita que essa resposta leva à mera legitimaçăo das diferenças. A segunda possibilidade seria o levantamento e a discussâo de temas (issues) sobre diversidade/diferença. Porém, Pennycook (2001) apresenta os principais problemas dessa resposta: trata a diversidade como preocupaçấo isolada, sugerindo que, por meio de uma discussâo racional, se possa chegar ao entendimento, em geral, tolerância, da diversidade. A terceira possibilidade seria o foco no engajamento (engagement), que percebe questóes de gênero, raça, classe, sexualidade - acrescentamos, em consonância com Bastos e Pessoa (2019), tamanho corporal - e assim por diante como centrais à noçâo de identidade e língua, portanto, fundamentais na organizaçăo curricular, na educaçăo linguística e na pesquisa.

Pennycook (2001) conclui, entăo, que perceber identidade como algo que performamos pela língua nos remete às consideraçōes de Foucault de que devemos considerar os efeitos de poder no corpo. Nesse sentido, precisamos compreender que o corpo gordo năo pode ser pensado apenas pela perspectiva de sua materialidade, visto que ele é parte constitutiva das identidades/subjetividades desse sujeito (CAETANO, 2019), que se dăo na e pela linguagem. Assim, o foco no engajamento com as diferenças nos trabalhos da LA crítica deve "incluir qualquer tema social desde que o foco esteja na desigualdade" (BASTOS; PESSOA, 2019, p. 17).

No cenário atual, cada vez mais trabalhos da LA têm se aproximado de agendas políticas, especialmente considerando seu caráter inter/trans/indisciplinar (MOITA LOPES, 2006). Em suma, "a questăo que se coloca é como lidar com a diferença com base na compreensăo de nós mesmos como outros, [...] defendendo a responsabilidade e a solidariedade para com o outro na vida social e em novas formas de conhecer" (MOITA LOPES, 2006, p. 89). O autor alerta para a necessidade de se preparar uma agenda de investigaçāo para a LA contemporânea que prevê "um novo modo de produzir conhecimento com implicaçóes sobre as mudanças na sociedade" (MOITA LOPES, 2006, p. 90). Em suas palavras, "năo se trata de levar a verdade/conhecimento a esses grupos, mas de construir a compreensăo da vida social com eles em suas perspectivas e vozes, sem hierarquizá-los" (MOITA LOPES, 2006, p. 96). Como alertam Kleiman, Vianna e De Grande (2019, p. 739), "[a] reflexâo contínua sobre seu próprio fazer, bem como a instituiçâo de um compromisso com uma agenda constantemente renovada de pesquisa [...] sâo itens essenciais a uma área que se quer atenta e sensível aos problemas do mundo social de seu tempo". 


\section{DESENHANDO AS CURVAS E AS CIRCUNFERÊNCIAS DO ESTUDO}

Este trabalho se constitui como uma pesquisa bibliográfica realizada a partir do levantamento de estudos no Catálogo de Teses e Dissertaçôes (CTD) da CAPES ${ }^{9}$, na Coleçâo de Periódicos da biblioteca eletrônica SciELO10 e na Biblioteca Digital de Teses e Dissertaçóes (BDTD)11. A busca nessas bases de dados teve como principal intento entender se e como o corpo gordo como uma questâo social tem sido foco de pesquisas realizadas no âmbito da LA no Brasil. A justificativa da escolha das plataformas de pesquisa CTD da CAPES, SciELO e BDTD é por serem três dos maiores portais de divulgaçăo científica do Brasil, com um enorme acervo bibliográfico, além de ser tecnologicamente de fácil acesso. Essas três plataformas săo fulcrais na otimizaçâo de conteúdo científico, centralizando trabalhos de diversas áreas do conhecimento, facilitando buscas interdisciplinares, ainda que nossas buscas tenham sido de forma "disciplinar".

Inicialmente, havíamos pensado em três palavras-tema para realizar as buscas nos bancos de pesquisa: "fat studies", "pressăo estética" e "gordofobia". Porém, acabamos por elencar 10 palavras-tema recorrentes em pesquisas sobre o assunto, pois acreditamos que assim poderíamos ampliar o escopo das buscas. Dessa forma, as palavras-tema usadas para as buscas foram: fat studies, fat people, fat acceptance, headless fatty, fatness, body positive, gordofobia, gorda, gordo e pressăo estética.

Após a escolha do tema e natureza da pesquisa, a próxima etapa foi pensar nos indicadores para refinamento das buscas. Inicialmente, planejamos seguir o esquema mostrado na Figura 2:

Figura 2: Esquema usado para refinamento de buscas nas bases bibliográficas

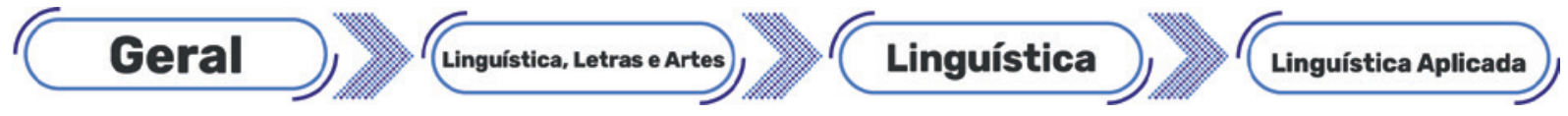

Fonte: Elaborado pel@s autor@s.

A busca pelas palavras-tema sem refinamento gerava milhares de resultados, como exemplificado na Figura 3 com o resultado geral de uma das palavras-tema de uma das bases pesquisadas.

9 O Catálogo de Teses e Dissertaçōes da Coordenaçăo de Aperfeiçoamento de Pessoal de Nível Superior (Capes) é um sistema de busca bibliográfica que reúne registros desde 1987. Possui como referência a Portaria n. 13/2006, que instituiu a divulgaçăo digital das teses e dissertaçóes produzidas pelos programas de doutorado e mestrado reconhecidos.

10 A plataforma SciELO (Scientific Electronic Library Online) é um portal que reúne um acervo digital de textos completos de revistas acadêmicas brasileiras. De acesso simples e gratuito. A SciELO é o resultado de um projeto de pesquisa da Fundaçấo de Amparo à Pesquisa de Săo Paulo (FAPESP) em parceria com o Centro Latino-Americano e do Caribe de Informaçăo em Ciências da Saúde (Bireme). A partir de 2002, esse projeto passou a contar também com o investimento e suporte do Conselho Nacional de Desenvolvimento Científico e Tecnológico (CNPq).

11 A BDTD integra os sistemas de informaçăo de teses e dissertaçôes existentes nas instituiçôes de ensino e pesquisa brasileiras. Estimula a publicaçáo de teses e dissertaçóes em meio eletrônico, dando maior visibilidade à produçấo científica nacional. 
Figura 3: Resultado quantitativo da busca no Catálogo de Teses e Dissertações da CAPES usando a palavra tema "fat studies" antes do processo de refinamento.

\section{8 resultados para Fat studies Exibindo 1-20 de 98508}

\section{Refinar meus resultados}

Fonte: Recorte de print de tela.

Porém, havia uma queda enorme no número de resultados quando iniciado o refinamento indicado na Figura 2. Durante o processo inicial de busca, percebemos que alguns trabalhos de linguistas aplicad@s com discussōes sobre o assunto estavam publicados na seçăo de "Ciências Sociais e Humanas", năo aparecendo nos resultados a partir do primeiro refinamento. No entanto, como o foco deste trabalho é analisar o percurso dessa temática na LA, optamos por nâo ampliar o escopo de pesquisa para outras áreas, mesmo tendo ciência desta limitaçăo do estudo. Também năo foram usados filtros de idioma, tipo de material ou delimitaçâo temporal, até porque as discussóes sobre corpos gordos dentro do campo científico sâo muito recentes.

A pesquisa exploratória nas bases bibliográficas selecionadas foi feita utilizando ferramentas de buscas disponíveis nas próprias plataformas. Os filtros utilizados contribuíram para a delimitaçăo de trabalhos que correspondiam às temáticas e áreas do conhecimento previamente escolhidas. Posteriormente, fizemos o download dos trabalhos encontrados a fim de realizar um processo de análise dos resumos e descartar os que porventura nâo tratassem do assunto pesquisado. No que concerne à etapa de descarte, excluímos todo trabalho que tratasse o corpo gordo apenas sob o aspecto clínico ou que se ligasse à área de Literatura. Realizada essa etapa, os trabalhos foram lidos na íntegra para um refinamento mais apurado da discussâo, o que levou a mais alguns descartes.

No CTD da CAPES, as buscas a partir das palavras-tema foram realizadas nos dias 19 e 20 de outubro de 2019. Como descrito anteriormente, no momento da busca exploratória usamos os marcadores presentes na plataforma para refinar a pesquisa. Dessa forma, no âmbito da grande área de pesquisa "Linguística, Letras e Artes", usando as 10 palavras-tema, encontramos dois trabalhos: um deles encontramos em três momentos, nas palavra-temas "fat studies", "gordofobia" e "gorda"; o segundo encontramos apenas quando usando a palavra-tema "gordo". O próprio portal de pesquisa delimita algumas opçōes de refinamento caso nâo haja trabalho dentro do tópico. E foi exatamente o que aconteceu referente à busca em LA: nenhum dos trabalhos encontrados no âmbito da grande área escolhida estavam cadastrados em estudos de LA.

No SciELO, as buscas pelas palavras-tema foram realizadas nos dias 22 e 23 de outubro de 2019. Da mesma forma que a busca anterior, no âmbito da grande área de pesquisa "Linguística, Letras e Artes", usando as 10 palavras-tema, encontramos seis trabalhos: um deles encontramos usando a palavra-tema "fat people", quatro usando a 
palavra-tema "body positive" e o último usando a palavra-tema "gordo", porém esse último foi descartado, pois "gordo" era apenas o sobrenome do autor do trabalho. Assim, encontramos um total de cinco trabalhos nessa plataforma na primeira delimitaçăo de busca. O SciELO năo fornecia a opçăo de LA e por isso năo foi possível, usando a busca exploratória, catalogar quais desses cinco resultados se encontravam em LA, processo que foi realizado na próxima etapa de leituras e análise dos trabalhos.

Na BDTD, as buscas a partir das palavras-tema foram realizadas nos dias 16, 17 e 18 de novembro de 2019. Seguindo o mesmo modo de buscas, no âmbito da grande área de pesquisa "Linguística, Letras e Artes", usando as 10 palavras-tema, detectamos cinco trabalhos, cada um deles em palavras-tema diferentes, sendo "fat studies", "fatness", "gordofobia" "gordo" e "gorda". Esse portal de pesquisa também delimita algumas opçôes de refinamento caso năo haja trabalho dentro do tópico. E, novamente, isso aconteceu referente à busca em LA: nenhum dos trabalhos encontrados no âmbito da grande área escolhida estavam registrados como diretamente ligados à LA.

Ao cruzar os resultados encontrados nas bases bibliográficas, alguns dos trabalhos detectados apareceram em mais de uma dessas bases, resultando, assim, um total de 10 trabalhos encontrados, sendo que um deles foi excluído por náo trabalhar a temática, restando para leitura e análise nove trabalhos em contexto brasileiro que discutem a temática do corpo gordo no âmbito da grande área de "Linguística, Letras e Artes", com foco nas discussôes de LA - ainda que năo tendo sido explicitamente registrados nas plataformas como pertencentes ao escopo da LA.

A análise foi realizada em uma abordagem qualitativa-interpretativista, baseada em indicadores e, posteriormente, uma leitura e sistematizaçăo dos dados (GUNTHER, 2006). Porém, năo excluímos da pesquisa a percepçâo quantitativa, pois acreditamos ser importante para a discussáo ter uma visâo numérica de quant@s pesquisador@s na área se interessam pela temática. Primeiramente, realizamos uma primeira leitura a fim de extrair informaçóes gerais de cada trabalho, área específica do estudo, escopo, contexto, data de publicaçáo e sujeitos envolvidos. A partir dessa leitura inicial geral, percebemos que quatro artigos se tratavam de estudos literários e năo foram levados em consideraçăo na análise. Sendo assim, foram analisados na íntegra cinco trabalhos. Durante a análise pormenorizada, percebemos que um dos trabalhos que havia passado por todos os outros critérios de seleçăo também nâo atendia ao propósito deste estudo e foi excluído do levantamento. Por fim, chegamos ao total de quatro trabalhos que podem indicar os caminhos que estăo sendo percorridos em pesquisas relacionadas ao corpo gordo como uma questăo social no âmbito da LA no Brasil. Discorremos sobre esses caminhos e desdobramentos no tópico a seguir.

\section{CORPOS GORDOS NO ESPELHO DA LINGUÍSTICA APLICADA}

Como detalhado na seçâo anterior, o refinamento analítico das buscas foi imprescindível para chegarmos aos trabalhos que, de fato, pudessem nos levar a responder se e como os corpos gordos estăo sendo estudados no escopo da LA brasileira. O Quadro 2 traz uma síntese dos trabalhos encontrados após o refinamento do levantamento de estudos no Catálogo de Teses e Dissertaçôes da CAPES, na Coleçăo de Periódicos da biblioteca eletrônica SciELO e na Biblioteca Digital de Teses e Dissertaçôes (BDTD), 
considerando a grande área "Linguística, Letras e Artes", as 10 palavras-tema escolhidas e sua possível relaçăo com a LA.

Quadro 2: Síntese dos trabalhos encontrados

\begin{tabular}{|c|c|c|c|c|c|c|}
\hline & Título & Autoria & Ano & Palavra-tema & $\begin{array}{c}\text { Base de } \\
\text { busca/ tipo de } \\
\text { publicação }\end{array}$ & Área \\
\hline 1 & $\begin{array}{l}\text { Histórias de uma } \\
\text { obesa: a teoria dos } \\
\text { posicionamentos e a (re) } \\
\text { construção discursiva } \\
\text { das identidades }\end{array}$ & $\begin{array}{l}\text { Claudia Almada } \\
\text { Gavina da Cruz; } \\
\text { Liliana Cabral } \\
\text { Bastos }\end{array}$ & 2015 & fat people & $\begin{array}{l}\text { SciELO/ } \\
\text { Artigo }\end{array}$ & Linguística \\
\hline 2 & $\begin{array}{l}\text { Representações e } \\
\text { identidades de mulheres } \\
\text { gordas em práticas } \\
\text { midiáticas digitais: tensões } \\
\text { entre vozes de resistência } \\
\text { e vozes hegemônicas }\end{array}$ & $\begin{array}{l}\text { Alexandra } \\
\text { Bittencourt de } \\
\text { Carvalho }\end{array}$ & 2018 & $\begin{array}{l}\text { fat studies; } \\
\text { gordofobia; } \\
\text { gorda }\end{array}$ & $\begin{array}{l}\text { CTD/Capes; } \\
\text { BDTD/ } \\
\text { Dissertação de } \\
\text { Mestrado }\end{array}$ & Linguística \\
\hline 3 & $\begin{array}{l}\text { "Você seria tão bonita, se } \\
\text { fosse magra": os múltiplos } \\
\text { sentidos no discurso da } \\
\text { superação da obesidade }\end{array}$ & $\begin{array}{l}\text { Ana Paula } \\
\text { Picagevicz }\end{array}$ & 2018 & fatness & $\begin{array}{l}\text { BDTD/ } \\
\text { Dissertação de } \\
\text { Mestrado }\end{array}$ & Linguística \\
\hline 4 & $\begin{array}{l}\text { Não tem cabimento: } \\
\text { corpo e subjetividade } \\
\text { no discurso de sujeitos } \\
\text { gordos }\end{array}$ & $\begin{array}{l}\text { Virgínia Barbosa } \\
\text { Lucena Caetano }\end{array}$ & 2019 & gordo & $\begin{array}{l}\text { BDTD/ } \\
\text { Dissertação de } \\
\text { Mestrado }\end{array}$ & Linguística \\
\hline
\end{tabular}

Fonte: Elaborado pel@s autor@s

O primeiro trabalho que analisamos foi um artigo de pesquisa das autoras Claudia Almada Gavina da Cruz e Liliana Cabral Bastos, intitulado "Histórias de uma obesa: a teoria dos posicionamentos e a (re)construçấo discursiva das identidades", publicada em 2015, no volume 15, n. 3 da Linguagem e (Dis)curso. Encontramos esse estudo na base bibliográfica SciELO com a palavra-tema "fat people". Uma das autoras desse trabalho era doutoranda em estudos linguístico e mestre em LA à época e o artigo em questăo trazia um recorte de sua pesquisa de doutoramento defendida nesse mesmo ano, porém sua tese (CRUZ, 2015) nâo foi localizada em nossas buscas no CTD/Capes e na BDTD. ${ }^{12}$ Esse artigo trata de um estudo a partir da narrativa de uma pessoa gorda, que em entrevista à pesquisadora relata o modo violento como pessoas de seu cotidiano se referiam a ela, causando-lhe transtornos de convivência, humilhaçăo e depressăo. As autoras do texto discutem a transitoriedade do corpo maior, ao observar as construçóes identitárias que emergem com os estigmas sociais construídos para esse corpo. Para Pinto (2016, p. 63), apesar de ser uma tarefa desafiadora entender que "o corpo possui linguagem e é linguagem e, se há linguagem, existem possibilidades de sentidos e náo sentidos" nos impulsiona a olhar para esse corpo gordo e os movimentos que o direcionam à margem. Fica nítido no estudo de Cruz e Bastos (2015) quáo tóxico e prejudicial esses padróes e estigmas săo aos corpos que estăo invisibilizados na

12 Acreditamos que o trabalho nâo tenha sido localizado por năo termos incluído as palavras-tema "obeso" e/ou "obesidade", visto que sâo termos negados pelo ativismo gordo. 
sociedade. Durante a análise, as discussōes săo pautadas majoritariamente em Análise do Discurso Crítica. O desconforto com o corpo dessa mulher năo surgiu por causa de limitaçôes físicas - tal como posto pelo discurso da saúde - mas sim por influência direta dos discursos - seja midiático, seja familiar - que a perpassava e a colocava em um lugar marginal, um corpo nâo adequado e que, portanto, náo está incluído nos padrôes aceitos socialmente. Segundo as autoras (CRUZ; BASTOS, 2015, p. 373) pensar sobre os efeitos da linguagem sobre as construçóes identitárias acirra o "debate necessário sobre a produçấo social das desigualdades e da exclusâo, o que, por sua vez, pode contribuir para redimensionar a visăo negativa que certos grupos de estigmatizados têm sobre si.". Ainda que o estudo se refira a uma entrevista, vários corpos gordos podem se ver reconhecidos nessa narrativa. Estudar esse discurso é colocar o tema em debate, resgatando-o da margem e reconhecendo o lugar de fala que ele denuncia. A violência perpetrada pela linguagem contra esse corpo auxilia a fortalecer o argumento que a língua, como performance, pode apagar subjetividades (PINTO, 2016).

O segundo trabalho que analisamos foi a dissertaçăo de mestrado de Alexandra Bittencourt de Carvalho, intitulada "Representaçôes e Identidades de mulheres gordas em práticas midiáticas digitais: tensôes entre vozes de resistência e vozes hegemônicas", defendida em 2018 no Programa de Pós-Graduaçáo em Letras da Universidade Federal de Viçosa. Esse estudo apareceu três vezes em duas bases bibliográficas, CDT da CAPES e na BDTD, usando as palavras-tema "fat studies", "gordofobia" e "gorda". Essa dissertaçāo trata do gordativismo pautado no movimento feminista, uma possível busca de identidades de mulheres gordas nas mídias sociais. Como dito pela própria autora, é uma mulher gorda falando para outras mulheres gordas que tudo bem, você pode ser gorda e estar bem e feliz. A autora relaciona teorias sociais sobre o corpo gordo - e sua aceitaçấo social - com as concepçóes de saúde/doença e beleza/feiúra. Sáo debatidas histórias e narrativas - produzidas em meio digital - de mulheres gordas para a construçấo do escopo do estudo entendido à luz do feminismo interseccional e da Análise do Discurso Crítica. Cabe lembrar que a pauta feminista visa recuperar a liberdade de expressăo das mulheres negado pelo patriarcado e busca fazer isso reconhecendo o lugar de fala que lhes têm sido historicamente negado e apagado (TIBURI, 2018). Carvalho (2018) situa seu estudo no campo do feminismo interseccional por entender que há em comum nos textos analisados em seu estudo fortes marcadores de opressâo incidindo sobre essas mulheres, como: definiçâo sócio-historicamente construída do padrâo magro como estética dominante, fortemente impulsionada pelo capitalismo; (nâo) aceitaçáo social do corpo gordo atrelado ao discurso de patologizaçăo; domesticaçăo sobre o corpo da mulher resultante das "representaçôes que os discursos hegemônicos fazem dele perpetuando sentidos investidos ideologicamente que contribuem para uma concepçâo negativa do corpo gordo feminino" (CARVALHO, 2018, p. 102). Como ressaltado no início deste estudo, Bauman (2010) nos alerta que consumo e desejo coexistem na atualidade de modo perverso. $O$ efeito disso no olhar sobre o corpo culmina em uma relaçăo conflituosa que se apresenta como liberdade de escolha, mas encobre uma dependência subserviente aos padróes ditados. Isso é ilustrado em Carvalho (2018) ao falar sobre campanhas publicitárias direcionadas ao público feminino gordo. A mídia opta por representar um corpo maior que "que se assemelha ao padráo simétrico do corpo" o que em sua análise faz com que a representatividade se torne "marginalizaçáo, pois itera o padrâo simétrico do corpo, mais 
uma vez negando a diversidade do corpo gordo." (CARVALHO, 2018, p. 90). Finalizando seu estudo, a autora pretende que ele seja "apenas um dos passos para que essa pauta seja disseminada e a gordofobia seja reconhecida como um preconceito estrutural e, portanto, como algo a ser combatido por todas e todos" (CARVALHO, 2018, p. 113).

O terceiro trabalho que analisamos foi a dissertaçâo de mestrado da Ana Paula Picagevicz, intitulada "Você seria tâo bonita, se fosse magra: Os múltiplos sentidos no discurso da superaçăo da obesidade", defendida em 2018, no Programa de PósGraduaçâo em Letras da Universidade Estadual do Oeste do Paraná - UNIOESTE. Encontramos esse trabalho na base bibliográfica BDTD com a palavra-tema "fatness". Nessa dissertaçâo é debatida a questâo de a "obesidade" ser vista como uma barreira a ser superada, bem como as construçôes desses discursos em uma plataforma digital de veiculaçáo de notícias. A autora discute a influência das mídias no processo de construir os objetivos do emagrecimento e do "sucesso" de se obter um corpo magro a qualquer custo. $O$ trabalho tem uma abordagem histórica, mostrando as mudanças nos padróes estéticos corporais ao longo dos séculos. A autora busca, por meio da leitura de imagens e de relatos em um portal de notícias sobre a superaçăo da obesidade, mostrar como o corpo gordo outrora representado como sinônimo de opulência, fartura e associado aos valores desejados tem sido relegado ao lugar de escárnio e marginalizaçáo. 0 estudo é conduzido pelas lentes teóricas da Análise do Discurso de linha francesa. Para Picagevicz (2018), o corpo gordo tem sido representado no espectro da transgressăo, haja vista que se "observados, na contemporaneidade, a partir da política de identidade e diferença, o diferente 'deve' ser colocado fora da fronteira do considerado 'normal' e ‘belo'; săo corpos considerados ameaças à norma." (PICAGEVICZ, 2018, p. 110, ênfase no original). 0 estudo nos mostra que apesar de gord@s maiores historicamente náo terem sido bem-vist@s socialmente, o padrăo alimentado recentemente pela mídia tem produzido efeitos de verdade que cada vez mais @s excluem. Para Pinto (2016), o imaginário social se institucionaliza pela frequência de repetiçáo de modelos e pela recorrência de figuras que atuam como um mecanismo de produçấo de sentidos. Trazendo esse raciocínio para nossa discussăo, podemos inferir que quanto mais vemos corpos gordos em situaçăo de margem, mais tendemos a vê-los como dissidentes, desviantes. Acentuadamente nos últimos anos houve uma transformaçăo significativa no modo como se vê o corpo. O corpo gordo passou a ser estigmatizado e "discursivizado de forma negativa, ao contrário do corpo magro, que é exaltado, náo só pela mídia, mas também pelo discurso médico e pela moda." (PICAGEVICZ, 2018, p. 105).

O quarto e último trabalho que analisamos foi a dissertaçăo de mestrado da Virgínia Barbosa Lucena Caetano, intitulada "Nâo tem cabimento: Corpo e Subjetividade no discurso de sujeitos gordos", defendida em 2019 no Programa de Pós-Graduaçáo em Letras do Centro de Letras e comunicaçăo da Universidade Federal de Pelotas. Encontramos esse trabalho na base bibliográfica BDTD, usando a palavra-tema "gordo". Essa dissertaçăo trata da pauta gordativista em uma perspectiva da psicanálise e da (re)produçáo de estereótipos nas diversas mídias/redes sociais. 0 escopo desse estudo é composto por quatro relatos anônimos entendidos também pelas lentes da Análise do Discurso francesa. Os textos foram selecionados a partir de uma amostra de 54 relatos produzidos no projeto digital intitulado Nâo tem Cabimento, desenvolvido na rede social virtual Tumblr. O projeto visava reunir e colocar em circulaçăo depoimentos de sujeitos que houvessem passado por algum episódio de gordofobia. Embora o recorte 
da pesquisa năo visasse gênero, mais uma vez essa questăo se fez relevante. Dentre os 54 relatos coletados apenas um foi escrito por homem. Isso aponta para o quanto a gordofobia assombra as mulheres. Os quatro textos analisados por Caetano (2019) corroboraram o que os demais estudos também já apontavam, ou seja, “o discurso da mídia e o discurso médico-científico sobre os corpos, de seu lugar hegemônico, produzem um processo de normatizaçăo e mercantilizaçăo da relaçăo dos sujeitos com seus corpos" (CAETANO, 2019, p. 100). Nessa dissertaçâo, a autora aponta para a urgência com que se deve estudar o impacto dos discursos construídos acerca do corpo gordo a fim de minorizar os males causados nas subjetividades desses indivíduos. Pinto (2016) afirma que no século XXI os corpos têm sido cada vez mais expostos e consumidos. Essa afirmaçăo nos transporta, ainda outra vez, à ideia desenvolvida por Bauman (2010) de que o consumo se manifesta pelo desejo de bens materiais e imateriais. 0 corpo ideal pode ser consumido com o auxílio da medicina que "comanda e exerce domínio sobre a vida das pessoas por meio do consumo de medicamentos, técnicas e terapias legitimados por um racionalismo científico" (CAETANO, 2019, p. 41), ainda que em detrimento da saúde mental das pessoas.

Ao final de nossa análise, nos deparamos com quatro estudos recentes produzidos nas regiōes Sudeste (CARVALHO, 2018) e Sul de nosso país (CRUZ; BASTOS, 2015; PICAGEVICZ, 2018; CAETANO, 2019) sob as lentes da Análise do Discurso (ora crítica, ora francesa). Os quatro estudos se assemelham na busca por entender o corpo gordo e sua representaçâo histórico e social elegendo como narrativas (relatos, entrevistas, depoimentos em portal de notícias) o lócus de representaçăo das subjetividades dos corpos gordos que narram suas dores na busca do corpo padrấo estabelecido pela mídia, agência de poder e controle dos meios de consumo em nosso sistema capitalista. Os discursos da saúde e do desejo de pertencimento pelo consumo sâo preponderantes nesses estudos. Em todos os casos, a violência e a opressăo se dăo e se revelam pela língua, o que nos alerta para a necessidade de discussâo desse tema por mais linguistas aplicad@s. Em comum, ainda, temos o recorte de gênero. Mulheres sendo invisibilizadas, segregadas e objetificadas pela ótica do patriarcado que dita suas regras e domestica os corpos. Urge que estudemos essa interseccionalidade em programas de stricto sensu e que façamos com que essas discussóes estejam presentes nas salas de aula, nos grupos de estudos e demais espaços formativos para que nos juntemos ao ativismo presente em mídias digitais, fortalecendo a militância, afinal, como afirma Tiburi (2018, p. 55), "quando lutamos por um lugar de fala lutamos pelo lugar de todos".

Os quatro estudos, bem como nossa busca nos bancos de dados (como descrito na seçâo anterior), apontam para uma lacuna de estudos sobre corpos gordos na LA em um contexto brasileiro que tenha um olhar mais plural para as dimensóes de nosso país. Precisamos estender esse olhar para outras regiōes e outros lugares de fala a fim de potencializar uma transformaçáo no modo como temos olhado para e nos expressado sobre nosso corpo. Afinal, entendemos como necessário provocar reflexóes referente a estigmas e opressóes que o corpo maior vivencia diariamente, nutridas pelo discurso hegemônico e gordofóbico. Como essas opressóes ocorrem quase sempre por meio da linguagem, pensamos que uma LA que se ocupe de questóes sociais deve se ater mais ao debate sobre corpos e suas interseccionalidades, como apontado por Wann (2009), buscando escapar de essencialismos. 
Um modo viável de fazer essa problematizaçăo alcançar um grande número de pessoas com potencial para repensar nosso futuro a partir de nossa agência em sociedade é trazê-la para as salas de aula por meio de praxiologias que se amparem na educaçấo linguística crítica. Ao expandir os estudos da linguagem para que englobem pautas sociais, oportunizamos que outras vivências, outros corpos sejam vistos e ouvidos. $\mathrm{O}$ contexto educacional pode favorecer que a violência seja dirimida ao incluir em seu espaço oportunidades de integraçăo da subjetividade corporal e da estética gorda. Nesse sentido, năo se busca tematizar a discussăo, mas sim incorporar nas atividades escolares textos - verbais e năo verbais - que explorem sentidos năo estigmatizados de corpos plurais (RAMOS-SOARES, 2020). Corpos gordos que ocupem diferentes posiçôes sociais e desempenhem diversas atividades, corpos nâo essencializados vistos em situaçōes cotidianas para que @s aprendizes realizem diferentes leituras desses materiais. Como ressaltado por Urzêda-Freitas (2012), uma abordagem crítica năo tem a pretensăo de transformar as aulas de línguas em aulas de sociologia, mas incluir o debate nas possibilidades que os próprios documentos educacionais oficiais oferecem. Convém lembrar que cabe a@s docentes - no exercício de sua agência - optar (ou náo) por promover oportunidades de problematizar temas vivenciais (SILVESTRE, 2016) na intençâo de questionar verdades socialmente construídas sobre padróes de beleza, estereótipos, tamanho corporal e bullying, ou quaisquer outras questóes que correntemente violentam os corpos que compóem o ambiente escolar. Usar o estranhamento que causa a imagem de um corpo maior ocupando posiçóes sociais e/ou profissionais de destaque para problematizar, por meio da linguagem, o processo de estigmas que esse corpo acarreta e a influência da mídia nesse processo pode ser uma transgressâo e um modo de interromper o processo de violências psicológicas, físicas e simbólicas a que sâo submetidos esses corpos (RAMOS-SOARES, 2020). Outra possibilidade de transgressâo seria intencionalmente gerar o estranhamento do termo "gord@", problematizando a forma como ele é lido socialmente e que sentidos sâo produzidos a partir dessas leituras.

Essas ideias surgem à guisa de instigar caminhos possíveis e năo de prescrever atividades, afinal, cada contexto faz emergir suas demandas e a sensibilidade docente é requerida para perceber como construir percursos mais inclusivos e plurais. Além disso, oportunizar a emersăo de diferentes narrativas sobre o tema, em que a problematizaçâo e a escuta sensível sejam exercidas, se mostra um desafio necessário. Acreditamos que esse é um caminho importante a ser percorrido por nós, linguistas aplicad@s, haja vista que entendemos a linguagem como prática social. Por meio da linguagem é possível construir sentidos outros que visem transformar as relaçóes sociais (PESSOA; URZÊEA-FREITAS, 2012). Oportunizar essas reflexóes pode possibilitar (re)pensar o corpo (gordo) em sua heterogeneidade em nossa sociedade atual, refutando a ideia de consumo e integrando as vozes, discursos e imagens diferentes que desse corpo emergem.

\section{VISLUMBRANDO UMA LINGUÍSTICA APLICADA GORDOATIVISTA}

Nosso principal intento com este trabalho esteve alicerçado na problemática de se e como estavam sendo realizadas pesquisas sobre a temática do corpo gordo como uma questăo social em produçóes brasileiras no escopo da LA. Inicialmente, foi pensado para este estudo usar apenas o Catálogo de Teses e Dissertaçăo da CAPES, porém 
decidimos aumentar o escopo de busca, tanto com as bases bibliográficas quanto com o número de palavras-tema, e, assim, visualizar de modo um pouco mais ampliado os caminhos percorridospel@s pesquisador@s linguistas aplicad@scom essa temática no Brasil. Ainda assim, entendemos que possa haver outros trabalhos relevantes sobre o tema que năo se encontram nas bases pesquisadas - por exemplo, a plataforma do Google Acadêmico, que náo foi utilizada por năo ter um processo de refinamento de buscas como precisávamos. Outra limitaçâo pode estar nas palavras-tema escolhidas, pois é provável que outras diferentes possam abarcar trabalhos que porventura náo tenham sido contemplados em nossas buscas.

Ainda que inserindo outras bases bibliográficas e pensando em novas palavras-tema, este estudo aponta para um número ainda muito reduzido de pesquisas em LA que discutem a pauta social de opressâo ao corpo gordo, o que, a nosso ver, deveria causar inquietaçâo à área. Tomando emprestado e ampliando uma questáo posta por Moita Lopes e Fabrício (2019, p. 716), "[c]omo é possível operar no campo aplicado dos estudos da linguagem sem tal intranquilidade, tendo em vista as perplexidades", exclusôes e sofrimentos que perseguem pessoas gordas cotidianamente? Assim, vislumbramos uma agenda de estudos que inclua as demandas postas pelo gordoativismo no campo aplicado dos estudos da linguagem.

A recente inclusâo dessa discussáo em duas das questôes do Exame Nacional do Ensino Médio (ENEM) de 2019 e no tema da redaçăo do Processo de Avaliaçăo Seriada (PAS 1) do mesmo ano incita esperança e nos alerta para a importância de que o corpo gordo como uma questáo social seja discutido e problematizado em nossas aulas de línguas na escola regular, bem como em outros contextos educacionais, e nos materiais didáticos utilizados nessas aulas. No ENEM, a questâo 02 do caderno azul do $1^{\circ}$ dia de provas trouxe o poema "Classifying" da escritora Judith Nichols. O poema trabalha algumas características físicas como ter sardas, usar óculos, ser alto ou baixo. Porém, a questăo em si năo sugere discussóes aprofundadas sobre estereótipos. O foco se dilui nas alternativas, que aludem a alguns termos como "intolerância às diferenças físicas" e "enunciar a diversidade", porém nâo eram as alternativas corretas da interpretaçâo do poema. Já a questăo 83 do caderno branco do $1^{\circ}$ dia de provas (ENEM/2019) trouxe um fragmento do texto "Um peso na alma: o corpo gordo e a mídia", das autoras Vasconcelos, Sudo e Sudo (2004). O fragmento utilizado problematiza a relaçăo do corpo gordo e o discurso médico que tanto o patologiza. Nas alternativas referentes à interpretaçâo desse texto estava presente a discussâo sobre "discursos hegemônicos" e "contestaçấo dos estereótipos consolidados" (que era a alternativa correta). Por sua vez, o PAS 1/2019 teve como tema da redaçấo "Aprenda ver beleza no diferente". A coletânea de textos para subsidiar a escrita foi composta por cinco pequenos textos que aludiam à problematizaçăo de estereótipos, concepçăo de beleza e de "estranho", compreensăo de estéticas diferentes em produçóes cinematográficas, direcionando para a problematizaçấo da questâo abstrata do que é "diferente" e da questăo de "beleza natural". A coletânea instigava @s candidat@s a demonstrar criticidade analítica na questâo de beleza padrâo e pluralidade de estéticas. Embora nâo houvesse explicitamente a mençăo a questôes corporais, havia espaço para que tais problemáticas emergissem nas produçōes textuais d@s candidat@s. Ainda que esses exemplos sejam localizados, entendemos que as pautas sociais lentamente têm ocupado mais espaço nos exames nacionais, o que pode acarretar mudanças nos conteúdos trabalhados nas instituiçōes educacionais. 
Isto posto, este estudo evidencia que ampliar o escopo de praxiologias em LA em nosso país com a temática gordoativista pode ser uma forma de contribuir para uma sociedade menos gordofóbica e mais inclusiva aos corpos marginalizados, especialmente pensando na relevância social dos estudos dessa área. Retomando uma das questóes postas em debates no dossiê do qual este texto é parte - Que problemas e/ou desafios do mundo atual interessam (ou podem interessar) à Linguística Aplicada? - defendemos que a causa gordoativista seja abraçada pela LA brasileira como um desafio do mundo atual de seu interesse.

Agora que você finalizou esta leitura, que tal voltar às questóes colocadas no início do texto e à colagem digital e perceber se as discussōes que trouxemos lhe ajudaram a refletir sobre as provocaçōes propostas de outro modo?

\section{AGRADECIMENTOS}

Agradecemos a Pedro Augusto de Lima Bastos e Letícia Gottardi pela leitura crítica à versăo preliminar deste texto e @s pareceristas pela avaliaçăo criteriosa e sensível deste manuscrito. Suas contribuiçōes foram muito importantes na (re)construçâo deste artigo. 


\section{REFERÊNCIAS}

BASTOS, Pedro Augusto de Lima; PESSOA, Rosane Rocha. A Discussion on English Language Students' Body Image: Beauty Standards and Fatness. Profile Issues in Teachers Professional Development, v. 21, n. 1, pp. 13-26, 2019.

BAUMAN, Zygmunt. Capitalismo parasitário. Rio de Janeiro: Zahar, 2010.

CAETANO, Virgínia Barbosa Lucena. "Năo tem cabimento": corpo e subjetividade no discurso de sujeitos gordos. 2019. 218f. Dissertaçâo (Mestrado em Letras) - Centro de Letras e Comunicaçăo, Universidade Federal de Pelotas, Pelotas, 2019.

CARVALHO, Alexandra Bittencourt de. Representaçóes e identidades de mulheres gordas em práticas midiáticas digitais: tensôes entre vozes de resistência e vozes hegemônicas. 2018. 149f. Dissertaçăo (Mestrado em Letras) - Departamento de Letras, Universidade Federal de Viçosa, Viçosa, 2018.

COOPER, Charlotte. Fat studies: mapping the field. Sociology Compass, v. 4, n. 12, pp. 1020-1034, 2010.

CRUZ, Claudia Almada Gavina da; BASTOS, Liliana Cabral. Histórias de uma obesa: a teoria dos posicionamentos e a (re)construçấo discursiva das identidades. Linguagem em (Dis)curso - LemD, Tubarăo, SC, v. 15, n. 3, pp. 367-384, set./dez. 2015.

CRUZ, Claudia Almada Gavina da. História é o que mais tem: narrativas e a construçâo discursiva das identidades de obesidade. 2015. 141f. Tese (Doutorado em Estudos da Linguagem) - Pontifícia Universidade Católica do Rio de Janeiro, Rio de Janeiro, 2015.

GUNTHER, Hartmut. Pesquisa Qualitativa Versus Pesquisa Quantitativa: Esta É a Questăo?. Psicologia: Teoria e Pesquisa, v. 22, n. 2, pp. 201-210, 2006.

GURGEL, Alexandra. Pare de se odiar: porque amar o próprio corpo é um ato revolucionário. Rio de Janeiro: Best Seller, 2018.

KLEIMAN, Angela B.; VIANNA, Carolina Assis Dias; DE GRANDE, Paula Baracat. A Linguística Aplicada na contemporaneidade: uma narrativa de continuidades na transformaçăo. Calidoscópio, v. 17, n. 4, pp. 724-742, 2019.

MARRA, Daniel da S.; REZENDE, Tânia F. Desobediência linguística: por uma epistemologia liminar que rasure a normatividade da língua portuguesa. Porto das Letras, v. 4, n. 1, pp. 174-202, 2018.

MOITA LOPES, Luiz Paulo da. Linguística aplicada e vida contemporânea: problematizaçăo dos construtos que têm orientado a pesquisa. In:__ (org.). Por uma linguística aplicada INdisciplinar. Sáo Paulo: Parábola, 2006. pp. 85-108.

MOITA LOPES, Luiz Paulo da; FABRÍCIO, Branca Falabella. Por uma 'proximidade crítica' nos estudos em Linguística Aplicada. Calidoscópio, v. 17, n. 4, pp. 711-723, 2019.

MORGAN, Brian. Post Structuralism and Applied Linguistics: Complementary Approaches to Identity and Culture in ELT. In: CUMMINS, Jim; DAVIDSON, Chris. 
(ed.). International Handbook of English Language Teaching. Norwell, MA: Springer Publishers, v. 2. pp. 949-968, 2007.

PENNYCOOK, Alastair. Critical Applied Linguistics: A Critical Introduction. New Jersey: Lawrence Erlbaum Associates, 2001.

PESSOA, Rosane; URZÊDA-FREITAS, Marco Túlio. Challenges in critical language teaching. Tesol Quartely, v. 46, n. 4, pp. 753-776, dez. 2012.

PETROSKI, Edio Luiz; PELEGRINI, Andreia; GLANER, Maria Fátima. Motivos e prevalência de insatisfaçăo com a imagem corporal em adolescentes. Ciência \& Saúde Coletiva, v. 17, pp. 1071-1077, 2012.

PICAGEVICZ, Ana Paula. “Você seria tăo bonita, se fosse magra": os múltiplos sentidos no discurso da superaçáo da obesidade. 2018. 144f. Dissertaçăo (Mestrado em Letras) Centro de Educaçăo, Comunicaçăo e Artes, Universidade Estadual do Oeste do Paraná, Cascavel, 2018.

PINTO, Danilo Corrêa. Corpos femininos produzidos pelo discurso da mídia para os desfiles de escola de samba do carnaval carioca. In: HASHIGUTI, Simone Tiemi; TAGATA, William Mineo (org.). Corpos, imagens e discursos híbridos. Campinas: Pontes, 2016. pp. 59- 76.

RAMOS-SOARES, Wilker. Onde estāo os corpos gordos? Um levantamento de estudos na Linguística Aplicada. 2019. Trabalho de Conclusāo de Curso - Universidade Estadual de Goiás, Anápolis, 2019.

RAMOS-SOARES, Wilker.. Papo de Menin@s: GORDOFOBIA NAS ESCOLAS - Como tem sido (re)construído as identidades corporais plurais no contexto educacional?. Webinar apresentado por Wilker Ramos Soares [Anápolis: YouTube. 05/08/2020], 2020. 1 vídeo (1h 31min 42 seg). Online. Publicado pelo canal Papo de Escola. Português. Disponível em: https://www.youtube.com/watch?v=8qoidliviL0. Acesso em: 10 ago. 2020.

RANGEL, Natália Fonseca de Abreu. A emergência do ativismo gordo no Brasil. In: $13^{\circ}$ CONGRESSO MUNDOS DE MULHERES(MM)ESEMINÁRIO INTERNACIONALFAZENDO GÊNERO (FG) 11, Florianópolis. Anais... Florianópolis: UFSC, 2017.

RANGEL, Natália Fonseca de Abreu. 0 ativismo gordo em campo: política, identidade e construçâoo de significados. 2018. 162f. Dissertaçăo (Mestrado em Sociologia Política) - Centro de Filosofia e Ciências Humanas, Universidade Federal de Santa Catarina, Florianópolis, 2018.

SILVESTRE, Viviane Pires Viana. Práticas problematizadoras e de(s)coloniais na formaçăo de professores/as de línguas: teorizaçôes construídas em uma experiência com o Pibid. 2016. 239f. Tese (Doutorado em Letras e Linguística) - Universidade Federal de Goiás, Goiânia, 2016.

TARDIF, Richard. The headless fatty: an effigy of hate, discrimination and intolerance, May 1, 2019. Disponível em: http://richardtardif.com/the-headless-fatty-the-body-the-belly-the-arse-food/. Acesso em: 27 abr. 2020.

TIBURI, Marcia. Feminismo em comum para todas, todes e todos. Rio de Janeiro: Rosa dos tempos, 2018. 
URZÊDA-FREITAS, Marco Túlio. Educando para transgredir: reflexóes sobre o ensino crítico de línguas estrangeiras/inglês. Trabalhos em Linguística Aplicada, v. 51, n. 1, pp. 77-98, jan./jun., 2012.

VASCONCELOS, Naumi A de; SUDO, Iana; SUDO, Nara. Um peso na alma: o corpo gordo e a mídia. Revista Subjetividades, v. 4, n. 1, pp. 65-93, 2004.

WANN, Marilyn. Fat studies: An invitation to revolution. New York: New York University Press, 2009. 